\title{
Activated carbonaceous materials from tea waste and its removal capacity of indigo carmine present in solution: synthesis, batch and optimization study
}

Dolanchapa Sikdar ${ }^{1,2^{*}}$, Sudipta Goswami ${ }^{1}$ and Papita Das ${ }^{1}$

\begin{abstract}
The present work determines efficiency of domestic food waste like tea waste in removing indigo carmine from synthetic textile wastewater. Carbonaceous material (tea waste) has been employed and it showed removal percentage of indigo carmine at $90 \%$ through adsorption process. Carbonaceous material was chemically activated by using modified Hummer's method and it was observed through Scanning Electron Microscopic image, Fourier Transform Infrared Spectrometer, X-ray diffractometer and Brunauer, Emmett and Teller analysis that revealed that the modified biochar is comparably similar to graphene oxide (GO). Various experimental parameters are evaluated for the removal efficiency of the synthesized adsorbent under the present study. Results of the experiments performed using the GO-like adsorbent synthesized from tea waste confirmed potential efficiency of adsorption of indigo carmine dye from synthetic waste water solution. The adsorption mechanism has been analysed by fitting the experimental data in different adsorption isotherm and kinetic models. The results indicated that the adsorption followed Langmuir isotherm model with maximum uptake of $20 \mathrm{mg} \mathrm{g}^{-1}$ and pseudo second order kinetic model with the best correlation coefficient. The thermodynamic study showed the dye removal to be spontaneous and endothermic.
\end{abstract}

Keywords: Indigo carmine (IC), Adsorption, Tea waste, Environmental pollution

\section{Introduction}

Dyes are a specific group of chemical pollutants, posing serious environmental problems, due to annual production in large amounts from different industrial sector like textile industry [1-3]. If this wastewater is released into a natural aquatic system, the photochemical activities of that aquatic system are adversely affected by the coloration of dye which reduces light penetration. Carcinogenic dyes might cause mutations in organisms $[4,5]$. Dyes are chemically designed and manufactured to be resistant to degradation by

\footnotetext{
* Correspondence: dolanchapasikdar88@gmail.com

'Department of Chemical Engineering, Jadavpur University, Kolkata 700032, India

${ }^{2}$ Department of Food Technology, Guru Nanak Institute of Technology, Kolkata 700114, India
}

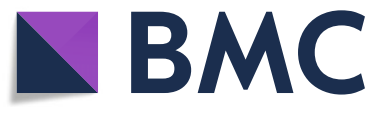

(อ The Author(s). 2020 Open Access This article is licensed under a Creative Commons Attribution 4.0 International License, which permits use, sharing, adaptation, distribution and reproduction in any medium or format, as long as you give

appropriate credit to the original author(s) and the source, provide a link to the Creative Commons licence, and indicate if changes were made. The images or other third party material in this article are included in the article's Creative Commons licence, unless indicated otherwise in a credit line to the material. If material is not included in the article's Creative Commons licence and your intended use is not permitted by statutory regulation or exceeds the permitted use, you will need to obtain permission directly from the copyright holder. To view a copy of this licence, visit http://creativecommons.org/licenses/by/4.0/. cannot be easily removed by the conventional wastewater treatments methods $[6,7]$.

Indigo carmine (IC) dye is widely present in wastewater produced from textile, food, cosmetic, pharmaceutical and paper industries [8-12]. According to WHO, the permissible limit of indigo carmine dye is $5 \mu \mathrm{g} \mathrm{L}^{-1}$ in water [13]. Wastewater containing IC dye must undergo treatment before discharging into the environment as it may cause skin and eye irritation, cancer to human [14-16]. Various methods that are based on aerobic or anaerobic biodegradation and photodegradation are not $100 \%$ efficient for removal of most of the dyes from wastewater. The various 
methods like chemical and electrochemical oxidations, coagulation, and reverse osmosis are costly when required to use in large scale [17-19]. In such a situation the technique of adsorption can be implemented in the removal of dyes.

Low cost adsorbents can be used, but the performance would vary according to the type of the dye. Activated carbon is processed to have low-volume pores and increased surface-area available for adsorption. Agricultural waste has shown a significant potential in manufacture of activated charcoal which can be used as adsorbent because of their abundance, easy availability and reusability. Various low-cost biomasses like potato peel, coffee waste, peanut shell, sunflower pith, and rice husk have been found to be a suitable precursor for bio-adsorbents which yield high carbon and less ash content [20-23]. Adsorption process is found to be an economical and easy method for wastewater treatment. The adsorbent utilised in this study for both batch and optimization study is synthesized from waste biomass namely; tea- waste that is converted into activated carbon in the form of biochar. The study has focused on a novel route of synthesis of chemically treated adsorbent under inert condition (nitrogen atmosphere) and higher tempe rature. With the chemical modification, the surface chemistry of the biochar is altered and eventually increases the oxygenated surface groups, thus enhancing the adsorption capacity of modified biochar than simple biochar [24]. Biochar that is produced from the thermochemical conversion of tea waste has limited oxygenated groups, surface area and low porosity. As a result, a suitable modification is essential to create oxygenated groups on the surface of the adsorbent. Use of oxidants like potassium permanganate $\left(\mathrm{KMnO}_{4}\right)$ and sulphuric acid $\left(\mathrm{H}_{2} \mathrm{SO}_{4}\right)$ have increased the oxygenated functional groups and the surface area of the adsorbent in significant amounts thereby increasing the performance of the adsorbent. The adsorption study was investigated by examining effect of various parameters like initial concentration of dye, $\mathrm{pH}$, temperature, adsorbent dosage and agitation speed on the dye removal performance. Optimization study of the adsorption process was carried out by using Response Surface Methodology (RSM). Adsorption models like Langmuir, Freundlich, Temkin isotherms were investigated and the respective curves compared. Kinetics (pseudo first order, pseudo second order and intraparticle model) and thermodynamics study of the adsorption process were also done in this research. Based on the experimental results, the lowcost adsorbent synthesized using tea waste as activated carbon can be suggested as a potential agent in adsorbing IC dye from synthetic wastewater.

\section{Materials and methods Materials}

IC, $\mathrm{KMnO}_{4}$, hydrogen peroxide, hydrochloric acid, sodium hydroxide, sulphuric acid were purchased from Merck India and used further without any modification. All the chemicals used in the study are of analytical grade.

\section{Preparation of adsorbent}

The tea waste has been collected from tea stall waste. In the first step the tea waste was thoroughly washed by distilled water to get rid of the coloured soluble compounds. After washing, the tea waste was dried at $100^{\circ} \mathrm{C}$ in a hot air oven. Then the biomass was placed inside the muffle furnace in a silica crucible and processed at $450{ }^{\circ} \mathrm{C}$ for $45 \mathrm{~min}$ in presence of $\mathrm{N}_{2}$ atmosphere for conversion of the tea waste to biochar. After completion of the process the biochar was taken out and cooled for $5 \mathrm{~h}$ [25]. Using the modified Hummer's method, carbonaceous material (tea waste) was treated [26] by strong oxidation process. A small amount of tea waste $(10 \mathrm{~g})$ was weighed and taken in an Erlenmeyer flask and $100 \mathrm{~mL}$ of concentrated $\mathrm{H}_{2} \mathrm{SO}_{4}$ is added slowly to flask with continuous stirring. After constant stirring of $20 \mathrm{~min}$, potassium permanganate is added to the solution for inducing the oxidation reaction. Distilled water $(100 \mathrm{~mL})$ is added to the flask after $30 \mathrm{~min}$ and the resulting mixture was kept in the incubator for $4 \mathrm{~h}$ at $45^{\circ} \mathrm{C}$. Afterwards, $70 \mathrm{~mL}$ of $\mathrm{H}_{2} \mathrm{O}_{2}$ was further added to terminate the reaction. The obtained solution was a brown coloured slurry. The slurry obtained was filtered using Whatman filter paper and the slurry was repeatedly washed using distilled water for $\mathrm{pH}$ neutralization. The filtered product is kept in hot air oven at $60{ }^{\circ} \mathrm{C}$ overnight; the dried product properly ground into powder and sifted through 60 mesh $(0.25 \mathrm{~mm})$.

\section{Adsorbate preparation}

IC stock solution was prepared by dissolving the dye powder in distilled water $\left(1000 \mathrm{mg} \mathrm{L}^{-1}\right)$. The desired amount of IC concentration was obtained by successive dilution of stock solution for preparing standard curve and further study.

\section{Batch equilibrium experimental studies}

Adsorption studies were conducted in $250 \mathrm{~mL}$ Erlenmeyer flask where $100 \mathrm{~mL}$ of IC solution had been placed having $20 \mathrm{mg} \mathrm{L}^{-1}$ concentration. An equal predetermined mass of adsorbent was incorporated to each one of the flasks and placed in the incubator shaker at $30^{\circ} \mathrm{C}$ for $2 \mathrm{~h}$ with an agitation speed of $120 \mathrm{rpm}$ to attain equilibrium. Various parameters to evaluate their effects were investigated during the studies including: adsorbent 
dosage $(0.5-0.25 \mathrm{~g})$, initial concentration of IC (10-50 $\left.\mathrm{mg} \mathrm{L}^{-1}\right)$, $\mathrm{pH}(2-12)$, temperature $\left(20-40^{\circ} \mathrm{C}\right)$, contact time (15-120 $\mathrm{min})$ and agitation speed $(80-150 \mathrm{rpm})$. The $\mathrm{pH}$ solution was maintained by using $1 \mathrm{M} \mathrm{NaOH}$ or $\mathrm{HCl}$ for the study. During the study, $2 \mathrm{~mL}$ of IC solution was sampled out at definite intervals of time and centrifuged (REMI PR 24) at 10,000 rpm for $15 \mathrm{~min}$. The supernatant solutions were then analysed using a UVVisible spectrophotometer $\left(\lambda_{\max }=610\right)$ (Lambda 25 Perkin Elmer). Each of the experiments was triplicated under identical conditions.

The percentage removal of IC was calculated by:

$$
\frac{C_{i}-C_{f}}{C_{f}} \times 100
$$

where, $C_{i}$ (initial) and $\mathrm{C}_{\mathrm{f}}$ (final) concentration $\left(\mathrm{mg} \mathrm{L}^{-1}\right)$ of IC respectively.

The amount of adsorption (IC on activated tea waste) at point of equilibrium,

$q_{e}\left(\mathrm{mg} \mathrm{g}^{-1}\right)$, was given by:

$$
q_{e}=\frac{\left(C_{i}-C_{e}\right) V}{M}
$$

where, $V=$ Working volume taken for the study (L), $M=$ dry adsorbent amount taken $(\mathrm{g}), C_{e}=$ equilibrium concentration of the dye $\left(\mathrm{mg} \mathrm{L}^{-1}\right)$.

\section{Adsorption isotherm models}

Isotherm models are important for adsorption study. Adsorption isotherm models indicate the relation between the amount of adsorbate onto the adsorbent at equilibrium state. Models like Langmuir, Freundlich, Temkin were considered to discuss the equilibrium condition of adsorption. The Langmuir model [27] suggests the monolayer adsorption with uniform surface of adsorbent, Freundlich model [28] suggests the heterogenous surface with multilayer adsorption and the linear reduction in the adsorbent surface molecules is suggested by Temkin model [29].

The Langmuir isotherm is calculated by the following equation:

$$
\frac{C_{e}}{q_{e}}=\frac{C_{e}}{Q}+\frac{1}{Q d}
$$

where $Q$ and $d=$ constants, ultimate adsorption capacity and adsorption constant, respectively.

The Langmuir isotherm model characteristic is expressed by a dimensionless separation factor $\left(R_{L}\right)$ [30]:

$$
R_{L}=\frac{1}{1+d C_{i}}
$$

When the value of $R_{L}$ is less than 0 , the isotherm type is not favourable, when the value of $R_{L}$ is equal to 1 , the isotherm type is linear and when $R_{L}$ ranges within 0 to 1 , the isotherm is favourable.

The Freundlich isotherm equation is shown by:

$$
\ln q_{e}=\frac{1}{c} \ln C_{e}+\ln \left(K_{f}\right)
$$

where, $K_{f}=$ Freundlich adsorbent capacity $\left(\mathrm{mg} \mathrm{g}^{-1}\right)$ and $c=$ Freundlich constant, surface heterogeneity factor.

The Temkin isotherm equation is shown by:

$$
q_{e}=R_{T} \ln C_{e}+R_{T} \ln K_{T}
$$

where, $R_{T}$ and $K_{T}=$ Temkin constants.

\section{Adsorption kinetic studies}

The kinetic behavior of an adsorbate removal or the absorption of a particular compound onto the surface of an adsorbent is important. The data from the batch studies were fitted to different kinetic models like pseudo-first order, pseudo-second order [31] and intraparticle diffusion model [32].

Pseudo-first order equation:

$$
\ln \left(q_{e}-q_{t}\right)=\ln q_{e}-k_{1} t
$$

where, $q_{t}=$ adsorbate amount (IC) per unit mass of adsorbent taken at $\mathrm{t}(\mathrm{h})$ (time) $\left(\mathrm{mg} \mathrm{g}^{-1}\right), k_{1}=$ constant adsorption rate $\left(\mathrm{h}^{-1}\right)$.

Pseudo-second order equation:

$$
\frac{t}{q_{t}}=\frac{1}{k_{2} q_{e}{ }^{2}}+\frac{t}{q_{e}}
$$

where, $k_{2}=$ rate constant of second order adsorption ( $\mathrm{g}$ $\mathrm{mg}^{-1} \mathrm{~h}^{-1}$ ).

Intraparticle diffusion model equation:

$$
q_{t}=k_{d} t^{1 / 2}+C
$$

where, $k_{d}=$ intraparticle diffusion rate constant $\left(\mathrm{mg} \mathrm{g}^{-1}\right.$ $\mathrm{h}^{-1 / 2}$ ).

\section{Thermodynamic studies}

The thermodynamic study determines the variation in standard enthalpy $\left(\Delta H^{o}\right)$, standard entropy $\left(\Delta S^{o}\right)$ and standard Gibb's free energy $\left(\Delta G^{o}\right)$ as:

$$
\begin{aligned}
& K_{c}=\frac{C_{a}}{C_{e}} \\
& \Delta G^{o}=-R T \ln K_{c} \\
& \Delta G^{o}=\Delta H^{o}-T \Delta S^{o}
\end{aligned}
$$

where, $K_{c}=$ distribution coefficient, $C_{a}=$ weight of dye adsorbed per unit mass of adsorbent $\left(\mathrm{mg} \mathrm{L}^{-1}\right)$ and $R=$ Universal gas constant $\left(8.31 \mathrm{~J} \mathrm{~mol}^{-1} \mathrm{~K}^{-1}\right)$. 


\section{Optimization analysis of the adsorption process by} design of experiments

RSM contains a set of statistical experimental techniques dealing with one or more response variables. Central Composite Design (CCD) was chosen for optimization of the experimental factors in the study. In the present research, CCD was employed to investigate the effect of different parameters effects like adsorbent dose, $\mathrm{pH}$, time for the adsorption study of IC dye onto activated carbonaceous material (tea waste).

A quadratic surface is fitted and identifying the interaction between experimental factors [33] in CCD (Design Expert Software version 7.2.0) and the number of experiments is reduced to $\mathrm{N}$ as given by Eq. (13).

$$
N=2^{k}+2 K+n_{o}
$$

where, $k=$ number of factors (parameters), $n_{0}=$ central point or replicate runs.

The main relationship between variables, interactions and response are formulated by using the following quadratic model equation:

$$
Y=\beta_{o}+\sum_{i=1}^{n} \beta_{i} X_{i}+\sum_{i=1}^{n} \beta_{i i} X_{i}^{2}+\sum_{i=1}^{n} \sum_{j=i+1}^{n} \beta_{i j} X_{i j}
$$

where, regression polynomial coefficients are $\beta_{0}$ : linear $\beta_{i}$ : quadratic, $\beta_{i i}$ and $\beta_{i j}$ : interaction, $x_{i}$ and $x_{j}$ are coded variables independent and $n$ is number (variable).

\section{Characterisation of activated carbonaceous material (tea waste)}

The $\mathrm{pH}$ of the point of zero charge $\left(\mathrm{pH}_{\mathrm{zpc}}\right)$ of the adsorbent synthesised was determined. To a series of conical, $50 \mathrm{~mL}$ of $\mathrm{NaCl}(0.01 \mathrm{M})$ was added and the $\mathrm{pH}$ values $(2,4,6,8,10,12)$ were adjusted by using $\mathrm{NaOH}$ or $\mathrm{HCl}$ (Eutech Instrument, $\mathrm{pH} 700$ ). After that $0.1 \mathrm{~g}$ of adsorbent was added to each conical. The suspension was agitated at room temperature $\left(30^{\circ} \mathrm{C}\right)$ for $24 \mathrm{~h}$. The variation in $\mathrm{pH}\left(\Delta \mathrm{pH}=\mathrm{pH}_{\mathrm{f}}-\mathrm{pH}_{\mathrm{o}}, \mathrm{pH}_{\mathrm{f}}=\mathrm{pH}_{\text {final }}\right)$ was determined and the plot of $\Delta \mathrm{pH}$ against $\mathrm{pH}_{\text {initial }}\left(\mathrm{pH}_{\mathrm{o}}\right)$ would indicate the $\mathrm{pH}_{\mathrm{zpc}}$ of the adsorbent.

Scanning Electron Microscopic (SEM) image (ZEISS EVO MA) was obtained to analyse the pore structure of the adsorbent produced. The acceleration volume was equal to $20 \mathrm{kV}$ and magnification was 5000 .

To analyse the chemical characterisation (functional groups) of the used adsorbent in this study, Fourier Transform Infrared Spectrometer (FT-IR) was used. The FT-IR analysis of the material was conducted from 400 to $4000 \mathrm{~cm}^{-1}$ by using pellets of $\mathrm{KBr}$ in a Perkin Elmer Spectrum Two.

To analyse the crystalline structure of the material, the patterns were recorded from X-ray diffractometer (XRD) operated at $40 \mathrm{kV}$ and $40 \mathrm{~mA}$ using $\mathrm{Cu} \mathrm{K} \alpha$ radiation while $2 \theta$ value ranges from 2 to $80^{\circ}$ (Shimadzu XRD 6000).

According to Brunauer, Emmett and Teller (BET) method, $\mathrm{N}_{2}$ adsorption-desorption isotherms at $77 \mathrm{~K}$ was used to determine the surface area and calculated using NOVA instruments.

\section{Regeneration study}

Adsorbent reusability plays an important role in adsorption-desorption study as well as recovery of adsorbate. The adsorbent was treated with acid $(\mathrm{HCl}) /$ base $(\mathrm{NaOH})$ for dye desorption studies. Cycle of adsorption-desorption study was repeated for 5 times to access the reusability of modified tea waste biochar in effective removal of indigo carmine dye.

\section{Results and discussion Effect of pH}

$\mathrm{pH}$ of the solution has important effect upon the adsorption process (Fig. 1a). The $\mathrm{pH}$ was varied from 2 to 12 and the removal of IC dye from the solution showed an increased sorption efficiency from 2 to 6 . The study shows a maximum percentage removal (93\%) at acidic state from $\mathrm{pH}$ (4-6). Higher removal efficiency at lower $\mathrm{pH}$ indicates the occurrence of protonation of the surface of adsorbent (activated tea waste) thus resulting in neutralization of negative charges and thereby providing more active sites leading to more adsorption. With further increase of $\mathrm{pH}$, deprotonation occurs and the adsorbent surface acquires more negative charged resulting in decreased removal efficiency and similar pattern was reported by Brito et al. [34] and Mittal et al. [35].

\section{Effect of adsorbent dosage}

Adsorbent dosage effect has been investigated by varying the dosage amount $\left(0.5-2.5 \mathrm{~g} \mathrm{~L}^{-1}\right)$ while keeping values of all other operational parameters constant (Fig. 1b). It has been observed that with the increase in dosage of adsorbent shows a significant sorption (95\%) was attained from 0.5 to $1 \mathrm{~g} \mathrm{~L}^{-1}$. With further increase of adsorbent dosage, there is no improvement of adsorption of IC. This is because of the fact of active adsorbent sites with the further increase in dosage exhibit less uptake of IC due to saturation or overlapping of active sites. These results are in agreement with others [36-38].

\section{Effect of initial concentration}

Influence of various concentration of IC dye was studied by adjusting the initial concentration of IC dye from 10 to $50 \mathrm{mg} \mathrm{L}^{-1}$ while keeping the other parameters to a fixed value and contact time at 1.75 

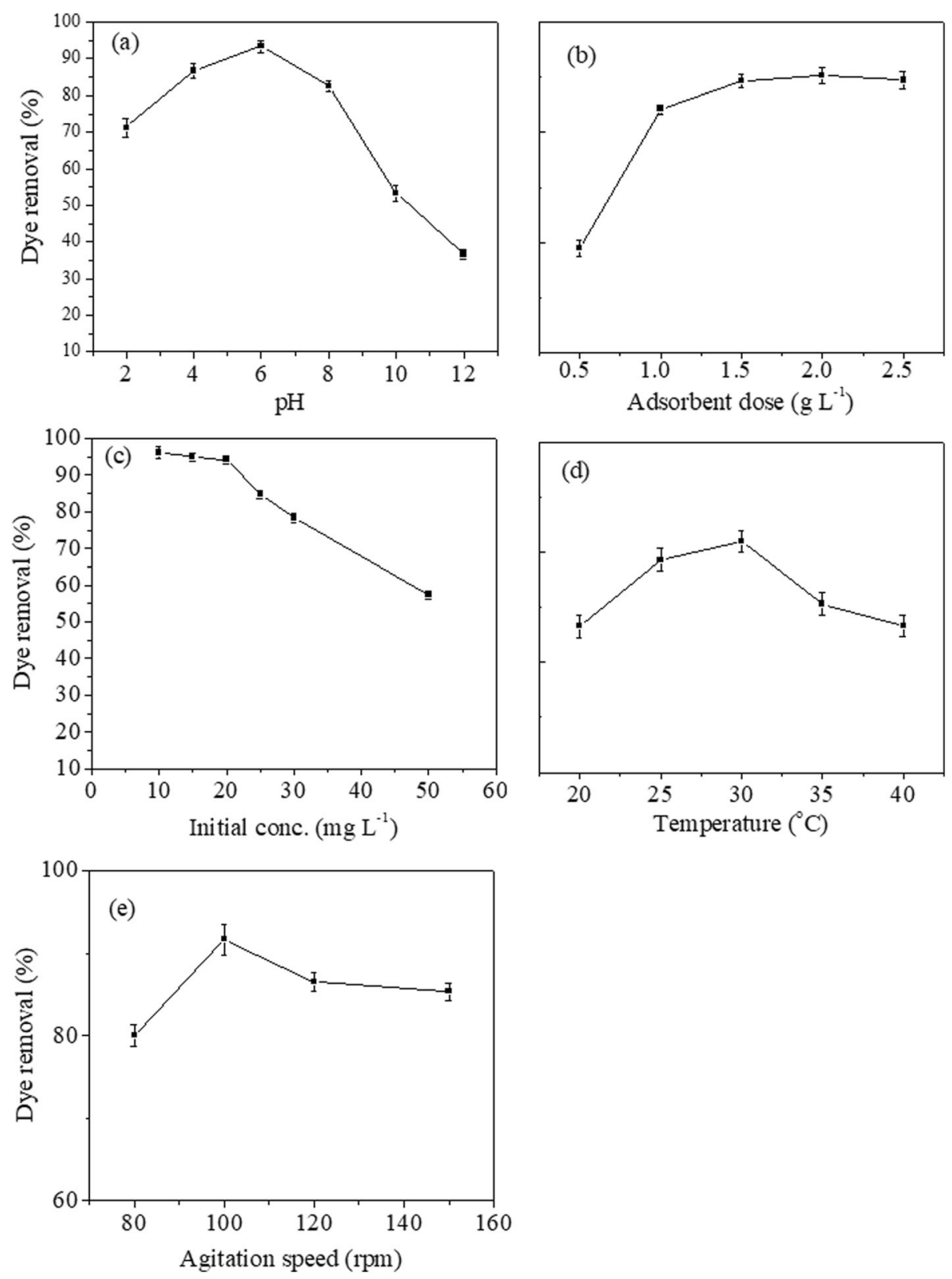

Fig. 1 depicts the effect of different parameters on IC dye adsorption onto activated carbonaceous material (tea waste). a-e represent the effect of $\mathrm{pH}$, adsorbent dose, initial concentration, temperature, agitation speed on the removal efficiency while keeping the other parameters of the experiment constant

h. From Fig. 1c, it can be observed that using a definite amount of adsorbent, \% removal of IC decreases from 96 to $64 \%$ as the initial concentration of IC is increased. The reason can be explained as initial concentration of the dye increases, the adsorption active sites get saturated or limited and hence less adsorption efficiency. The same observation was reported by Mittal et al. [35] and Ramesha et al. [39].

\section{Effect of temperature}

Rate of adsorption rate depends upon the temperature and shows the thermodynamic nature of the process. The temperature range was varied from 20 to $40^{\circ} \mathrm{C}$. The adsorption efficiency was found to be increasing with the elevation of temperature. The maximum removal percentage (91\%) was found at $30^{\circ} \mathrm{C}$. Further temperature increase beyond $30^{\circ} \mathrm{C}$ showed a decrease in removal percentage of IC dye (Fig. 1d). The reason 
might be weakening of the forces among adsorbent active sites and dye moieties at higher temperature as suggested by Mukherjee et al. [40]. The rate of removal is accelerated with the rising temperature and thus again it confirms the nature of the adsorption process of adsorbent to be endothermic.

\section{Effect of agitation speed}

The agitation speed was varied from 80 to $150 \mathrm{rpm}$ to study its effect on dye adsorption capacity on to the adsorbent. The homogenous suspension with better removal was found at $100 \mathrm{rpm}$ (Fig. 1e); the increased agitation speed further showed a decrease in removal efficiency. Thus, for the further study, $100 \mathrm{rpm}$ was used for the experiment.

\section{Process isotherm}

Experimental data obtained from the study were fitted into Langmuir (Fig. 2a), Freundlich (Fig. 2b) and Temkin (Fig. 2c) isotherms. The theoretical parameters with determined coefficients of different isotherm models are listed in Table 1. The results show the best fitted isotherm model is Langmuir with the highest regression coefficient $\left(R^{2}=0.99\right)$ obtained with adsorbent dosage of $0.1 \mathrm{~g}, 100 \mathrm{~mL}$ working volume, temperature $30^{\circ} \mathrm{C}$, initial concentration of dye $20 \mathrm{mg} \mathrm{L}^{-1}$ and agitation speed 100 rpm. Langmuir adsorption model assumes that at specific sites of a homogenous surface of the adsorbent comprising fixed number of identical sorption sites, adsorption occurs and adsorption process ceases as the saturation of these sites. The adsorption is limited to the monolayer layer coverage of the adsorbate. Similar observations were reported where methylene blue adsorption onto corncob prepared activated carbon [41] and jute fiber [42].

The parameter $\mathrm{C}_{\mathrm{e}} / \mathrm{q}_{\mathrm{e}}$ is plotted against $\mathrm{C}_{\mathrm{e}}$ in Langmuir isotherm, from where a straight line is found. The Langmuir constants $\mathrm{Q}$ and $\mathrm{d}$ are calculated from Eq. (3). The essential factor of Langmuir adsorption isotherm is calculation of dimensionless separation factor $\left(R_{L}\right)$ (Eq. (4)). The value of $R_{L}$ is favourable when it ranges from $0<$ $R_{L}<1$ [41] and was found to be 0.4 . This again indicates the favorability of Langmuir isotherm for adsorption of IC dye on the adsorbent.

\section{Process kinetics}

In case of pseudo-first-order kinetics, the $k_{1}$ value was acquired from the slope of the plot of $\ln \left(q_{e^{-}} q_{t}\right)$ vs. $t$ (Eq. (7)). Pseudo-second-order-kinetic model is studied by plotting $\mathrm{t} / \mathrm{q}_{\mathrm{t}}$ vs. $\mathrm{t}$ (Eq. (8)). A linear relationship is obtained and $k_{2}$ (from intercept), $q_{e}$ (from slope) values are calculated. Intraparticle diffusion model is obtained by plotting $q_{t}$ versus $t^{1 / 2}$ and $k_{d}$ (Eq. 9) is determined from the slope of the linear equation.
The values of $\mathrm{R}^{2}$ obtained from the plots of the pseudo-first- order kinetic, pseudo-second-order-kinetic and intraparticle diffusion models were compared and it was found that the process is guided by pseudo-second-order kinetic model. For, pseudo-firstkinetic, $q_{e}\left(8.0 \mathrm{mg} \mathrm{g}^{-1}\right), k_{1}\left(0.025 \mathrm{~h}^{-1}\right)$ and regression coefficient (0.881), pseudo-second-order kinetic, $q_{e}$ $\left(21 \mathrm{mg} \mathrm{g}^{-1}\right), k_{2}\left(4.5 \mathrm{~h}^{-1}\right)$, regression coefficient $(0.997)$, intraparticle diffusion $k_{d}\left(6.6 \mathrm{mg} \mathrm{g}^{-1} \mathrm{~h}^{-1 / 2}\right), \mathrm{C}(9.9 \mathrm{mg}$ $\mathrm{g}^{-1}$ ) and regression coefficient 0.978 could be seen from calculation. The pseudo second order model is best fit by interpreting the kinetics data of the adsorption process shown in Fig. 3.

\section{Process thermodynamics}

The values $\Delta H^{o}$ and $\Delta S^{o}$ (Table 2) were established from the slope and intercept obtained plotting $\ln K_{d}$ vs $1 / T$ (Fig. 4). The nature of adsorption interaction is endothermic as indicated by the positive value of $\Delta H^{\circ}$. The value of $\Delta S^{o}$ is positive and described the affinity of activated carbonaceous material (tea waste) and that demonstrated the randomness at solid-solute interface. The negative value of $\Delta G^{o}$ suggested the spontaneity of the adsorption nature and with temperature elevation, the value decreased.

\section{Process optimization}

The results of percentage removal (\%) are shown in the Table 3 by experiments (total: 20) recommended by RSM (CCD). F-value (61) was found to be best fitted at quadratic model $(p<0.0001)$. The coefficient (regression) values: $R^{2}$ (0.937), adjusted $R^{2}$ (0.925), predicted $R^{2}(0.905)$ for adsorption of IC dye onto activated carbonaceous material (tea waste) suggest quadratic polynomial model is better than other models that are tested. The Adeq (precision for adsorption of IC dye) was found as 13 and the theoretical \% IC removal was found using the following semi-empirical equation.

$$
\begin{aligned}
\text { Percentage removal } & =3.06+1.35 * \mathrm{pH}+0.0159 * \text { Adsorbent Dose }(\mathrm{mg}) \\
& -1.49 * \text { Time }(\mathrm{min})-4.14 * \mathrm{pH} * \text { aAdsorbent Dose }(\mathrm{mg}) \\
& -3.76 * \mathrm{pH} * \text { Time }(\mathrm{min}) \\
& +1.12 * \text { Adsorbent Dose }(\mathrm{mg}) * \text { Time }(\mathrm{min}) \\
& -0.0998 * \mathrm{pH}^{2}-5.46 * \text { Adsorbent Dose }(\mathrm{mg})^{2} \\
& -4.55 * \operatorname{Time}(\mathrm{min})^{2}
\end{aligned}
$$

Figures 5 and 6 show the result of RSM analysis of IC dye adsorption. The inter parameter interactions of the ANOVA model will be discussed below.

\section{Effect of variation of $\mathrm{pH}$ and adsorbent dose}

3D response form as presented in Fig. 5a shows that percentage removal of IC dye with the mutual effect of $\mathrm{pH}$ 
(a)

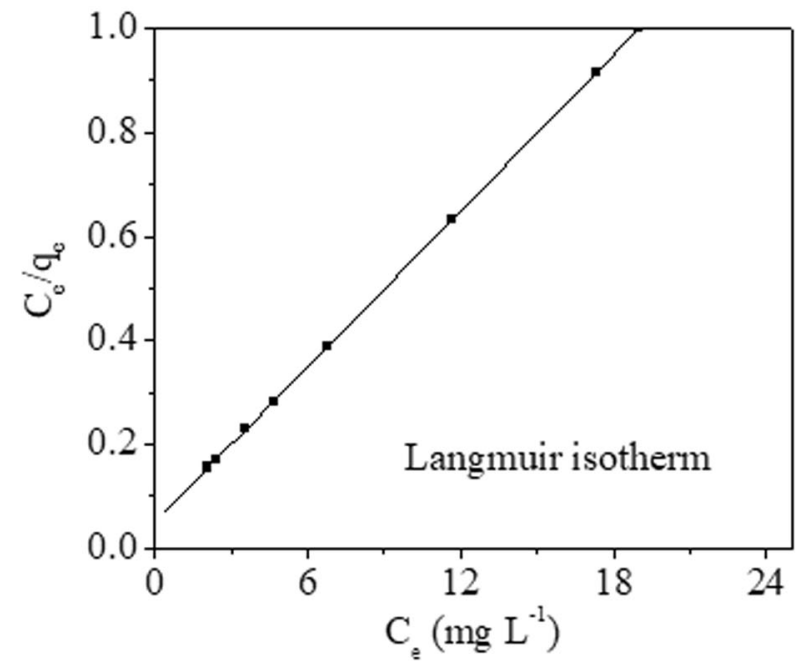

(c)

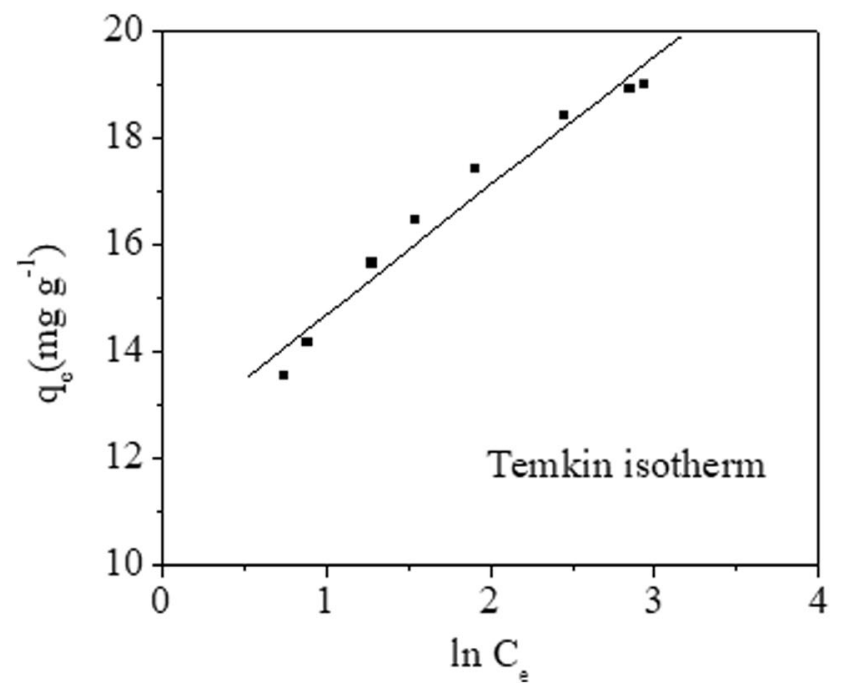

(b)

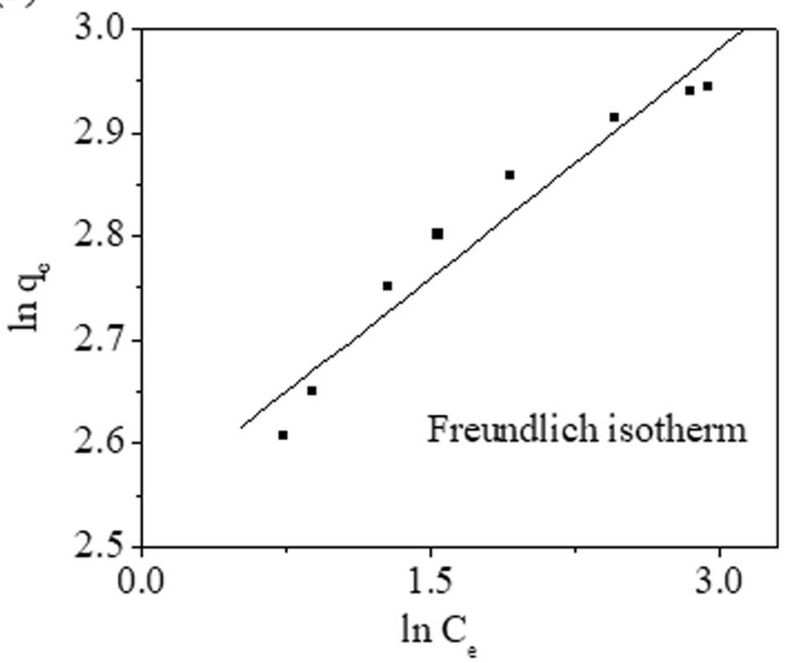

Fig. 2 shows the Langmuir, Freundlich and Temkin adsorption isotherm respectively of IC dye onto activated carbonaceous material (tea waste)

and adsorbent dose at constant time. Graphs indicate an increase of response function with the elevation of $\mathrm{pH}$ up to a certain limit and then the response function shows a reverse trend. The fact may be due to the fact that accessibility of active sites increases with increase of $\mathrm{pH}$ and but beyond a certain limit, the saturation of such active sites occurs.

\section{Effect of variation of $\mathrm{pH}$ and reaction time}

$\mathrm{pH}$ and reaction time were considered in this process. 3D graph from Fig. 5b shows the interactive effect of both the parameters at constant adsorbent dose. The increase in $\mathrm{pH}$ in solution shows the increase of response function with increase of reaction time. The result was found to be consistent with the batch result.

Table 1 shows the adsorption isotherm model parameters and correlation coefficients for adsorption of IC dye on activated carbonaceous material (tea-waste)

\begin{tabular}{|c|c|c|c|c|c|c|c|c|}
\hline \multicolumn{3}{|l|}{ Langmuir } & \multicolumn{3}{|l|}{ Freundlich } & \multicolumn{3}{|l|}{ Temkin } \\
\hline$Q\left(\mathrm{mg} \mathrm{g}^{-1}\right)$ & $d\left(\mathrm{~L} \mathrm{mg}^{-1}\right)$ & $R^{2}$ & $K_{f}\left(\mathrm{mg} \mathrm{g}^{-1}\right)$ & $c$ & $R^{2}$ & $R_{T}\left(\mathrm{~J} \mathrm{~mol}^{-1}\right)$ & $K_{T}\left(\mathrm{~L} \mathrm{~g}^{-1}\right)$ & $\mathrm{R}^{2}$ \\
\hline 20 & 1.56 & 0.99 & 12.6 & 6.8 & 0.971 & 2.4 & 161 & 0.98 \\
\hline
\end{tabular}




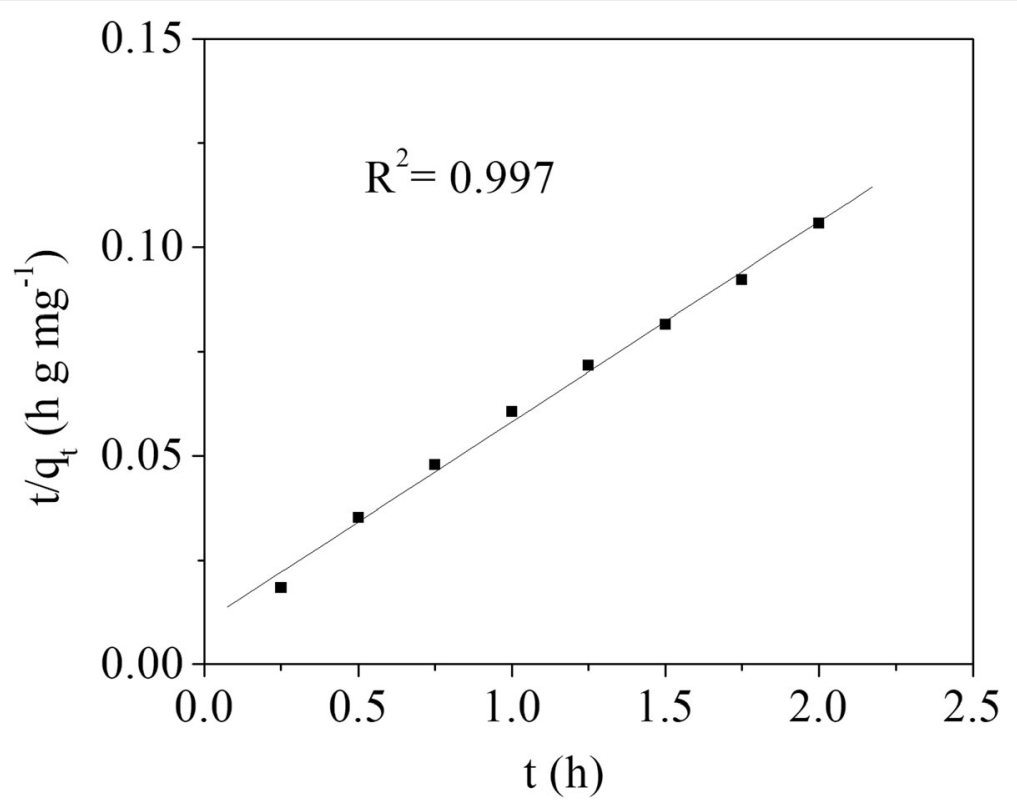

Fig. 3 show the Pseudo-second order kinetics for of IC dye adsorption onto activated carbonaceous material (tea waste)

\section{Effect of variation of adsorbent dose and reaction time}

The combined effect of adsorbent dose and reaction time was observed at constant $\mathrm{pH}$. The adsorbent dose with time shows an increase of response function (\% removal) of IC dye (Fig. 5c). This is because of the adsorbent active sites availability with elevation of reaction time and thus higher adsorption of IC dye from the solution onto adsorbent and the results show the similarity with the batch studies.

\section{Optimization of reaction condition}

The results generated from Design Expert Software (version 7.2.0) predict the optimum conditions of the study using quadratic model. A maximum percentage removal (89\%) was obtained from the optimization model using optimum $\mathrm{pH} 6$, adsorbent dose $50 \mathrm{mg}$ and reaction time $120 \mathrm{~min}$. Comparing the predicted $R^{2}$ and the corresponding $R^{2}$ from the experimental data (Fig. 6) shows a good agreement and thus indicates the suitability of the model to optimize the reaction condition.

Table 2 Thermodynamic parameters for adsorption of IC dye onto activated carbonaceous material (tea-waste)

\begin{tabular}{lcccccc}
\hline$\Delta \boldsymbol{H}^{\boldsymbol{o}}\left(\mathrm{J} \mathrm{mol}^{-\mathbf{1}}\right)$ & $\Delta \boldsymbol{S}^{\boldsymbol{o}}\left(\mathrm{J} \mathrm{mol}^{-\mathbf{1}} \mathbf{K}^{-\mathbf{1}}\right)$ & $\Delta \boldsymbol{G}^{\boldsymbol{o}}$ & $\left(\mathrm{J} \mathrm{mol}^{-\mathbf{1}}\right)$ & & & \\
\hline 60 & 2.9 & $293 \mathrm{~K}$ & $298 \mathrm{~K}$ & $303 \mathrm{~K}$ & $308 \mathrm{~K}$ & $313 \mathrm{~K}$ \\
& & -787 & -801 & -816 & -830 & -845 \\
\hline
\end{tabular}

\section{Characterization of adsorbent}

It was found that the surface of the adsorbent is slightly acidic (Fig. 7). According to the study, the $\mathrm{pH}_{\mathrm{zpc}}$ of the adsorbent surface was found to be at around 5.6 and the experimental batches were carried out further with $\mathrm{pH}=$ $\mathrm{pH}_{\text {zpc }}$ as suggested by Mullet et al. [43].

SEM image showed the surface morphology of the adsorbent. The structure of the unmodified tea waste biochar and modified biochar, i.e., activated carbonaceous material is shown in the Fig. $8 \mathrm{a}$ and b, respectively. The micrograph shows the external surfaces of the treated tea waste biochar are folded and some have various large holes, cracks and the overlapping thin layers show similarity with the structure GO as produced from the graphite. The image obtained from SEM in this study shows similar result as reported by Banerjee et al. [36] and Goswami et al. [25].

The FT-IR spectroscopy shows a peak at $3549 \mathrm{~cm}^{-1}$ (Fig. 9) showing a stretching of $\mathrm{O}-\mathrm{H}$ groups. A good peak was found at $2924 \mathrm{~cm}^{-1}$ representing a C-H stretching of alkene groups [28]. The $1023 \mathrm{~cm}^{-1}$ band a strong $\mathrm{C}-\mathrm{O}$ stretching of alcoholic group. The results are consistent with Banerjee et al. [36] and Angin [44].

A prominent peak could be seen at 24.9 (Fig. 10) in the XRD analysis graph. The hump in the $2 \theta$ from 20 to 30 indicates a highly expected degree for the produced material to be carbonaceous and these results are accordance to Koseoglu and Akmil-Basar [45]. 


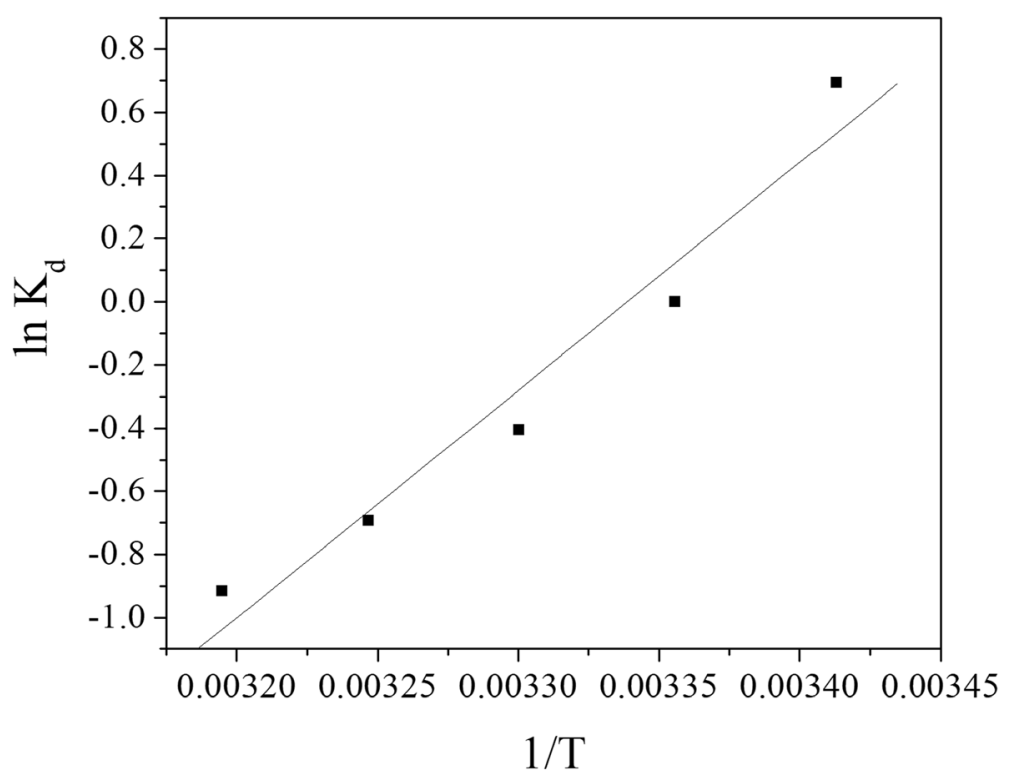

Fig. 4 Plot of In $K_{d}$ vs $1 / T$ for IC dye adsorption

Table 3 Experimental details along with results obtained in the Response Surface Methodology optimization of Indigo Carmine dye onto activated carbonaceous material (tea-waste)

\begin{tabular}{|c|c|c|c|c|c|}
\hline \multirow[t]{2}{*}{ Factors } & & \multirow[t]{2}{*}{ Units } & \multicolumn{3}{|l|}{ Levels } \\
\hline & & & Low $(-1)$ & Medium (0) & High (+ 1) \\
\hline $\mathrm{pH}$ & & & 2 & 6 & 12 \\
\hline Adsorbent dose & & $\mathrm{mg}$ & 50 & 130 & 81 \\
\hline Time & & $\min$ & 15 & 72 & 120 \\
\hline Run & Factor 1: $\mathrm{pH}$ & Factor 2: Adsorbent dose & Factor 3: Time & Response: $\mathrm{P}$ & \\
\hline 1 & 2 & 250 & 15 & 44 & \\
\hline 2 & 7 & 68 & 120 & 80 & \\
\hline 3 & 6 & 50 & 15 & 30 & \\
\hline 4 & 12 & 250 & 120 & 42 & \\
\hline 5 & 12 & 250 & 120 & 42 & \\
\hline 6 & 6 & 50 & 57 & 65 & \\
\hline 7 & 2 & 250 & 82 & 50 & \\
\hline 8 & 6 & 175 & 57 & 82 & \\
\hline 9 & 7 & 120 & 15 & 67 & \\
\hline 10 & 8 & 250 & 15 & 52 & \\
\hline 11 & 6 & 169 & 120 & 88 & \\
\hline 12 & 6 & 50 & 120 & 20 & \\
\hline 13 & 12 & 50 & 15 & 30 & \\
\hline 14 & 2 & 121 & 15 & 38 & \\
\hline 15 & 2 & 50 & 120 & 32 & \\
\hline 16 & 2 & 124 & 80 & 63 & \\
\hline 17 & 6 & 50 & 120 & 20 & \\
\hline 18 & 12 & 168 & 57 & 32 & \\
\hline 19 & 6 & 50 & 57 & 65 & \\
\hline 20 & 2 & 50 & 120 & 32 & \\
\hline
\end{tabular}



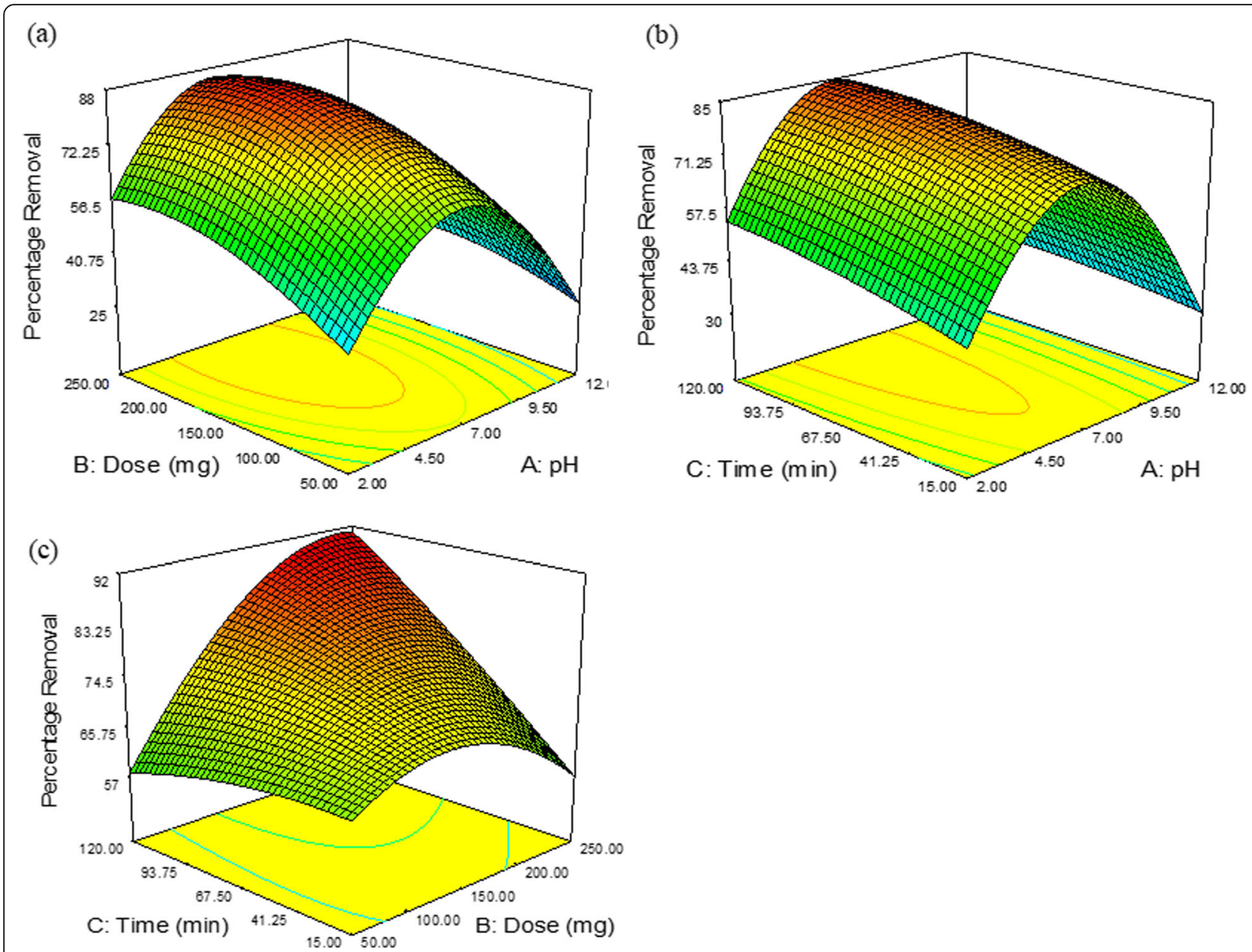

Fig. 5 Parameter interaction effect on adsorption of IC dye by activated carbonaceous material (tea waste) as acquired from Response Surface Methodology (RSM) analysis. a-c show the 3D plots implying the interactions impact of solution pH vs. adsorbent dose, pH vs. reaction time, adsorbent dose vs. reaction time on percentage removal (\%) of IC dye respectively

The obtained prominent peak (24.9) of activated carbonaceous material showed similar GO peaks as reported in a previous investigation [46] and thus, indicating the desired GO like structure synthesis in the present study.

The tea waste biochar both untreated and treated (chemically) were subjected to $77 \mathrm{~K}$ for the comparative study of BET surface area. With the application of chemical and thermal treatment, the surface area of treated tea waste biochar increased $\left(32 \mathrm{~m}^{2} \mathrm{~g}^{-1}\right)$ as compared to the untreated tea waste $\left(15 \mathrm{~m}^{2} \mathrm{~g}^{-1}\right)$. Treated tea waste biochar has total pore volume of $0.026 \mathrm{cc} \mathrm{g}^{-1}$ with pore radius smaller than $196 \mathrm{~nm}$ and untreated tea waste biochar with pore volume of $0.0098 \mathrm{cc} \mathrm{g}^{-1}$ with pore radius smaller than $155 \mathrm{~nm}$. The results obtained indicate that the surface area, pore volume and average pore size all increase with the utilization of oxidizing agents in treated carbonaceous tea waste biochar as compared to untreated tea waste bio char and thus could be the reason for better adsorption. The results are in agreement with study reported by Tushar et al. [47].

\section{Recyclability analysis of the adsorbent}

Adsorbent-desorption studies were performed with activated carbonaceous material to determine the effective reusability of the IC dye. In the present study, the number of tests was conducted with a solution of $\mathrm{NaOH}$ with $100 \mathrm{~mL}$ working volume of 20 $\mathrm{mg} \mathrm{L}^{-1}$ as initial concentration of the solution for each cycle. The performance of the regenerated adsorbent in \% removal of IC dye vs. number of cycles is plotted (Fig. 11). The observation shows the removal efficiency of the adsorbent is around 90\% till 2nd cycle and reduced to 80 and $78 \%$ at 4 th and 5th cycle, respectively, and thus establishing the fact of 


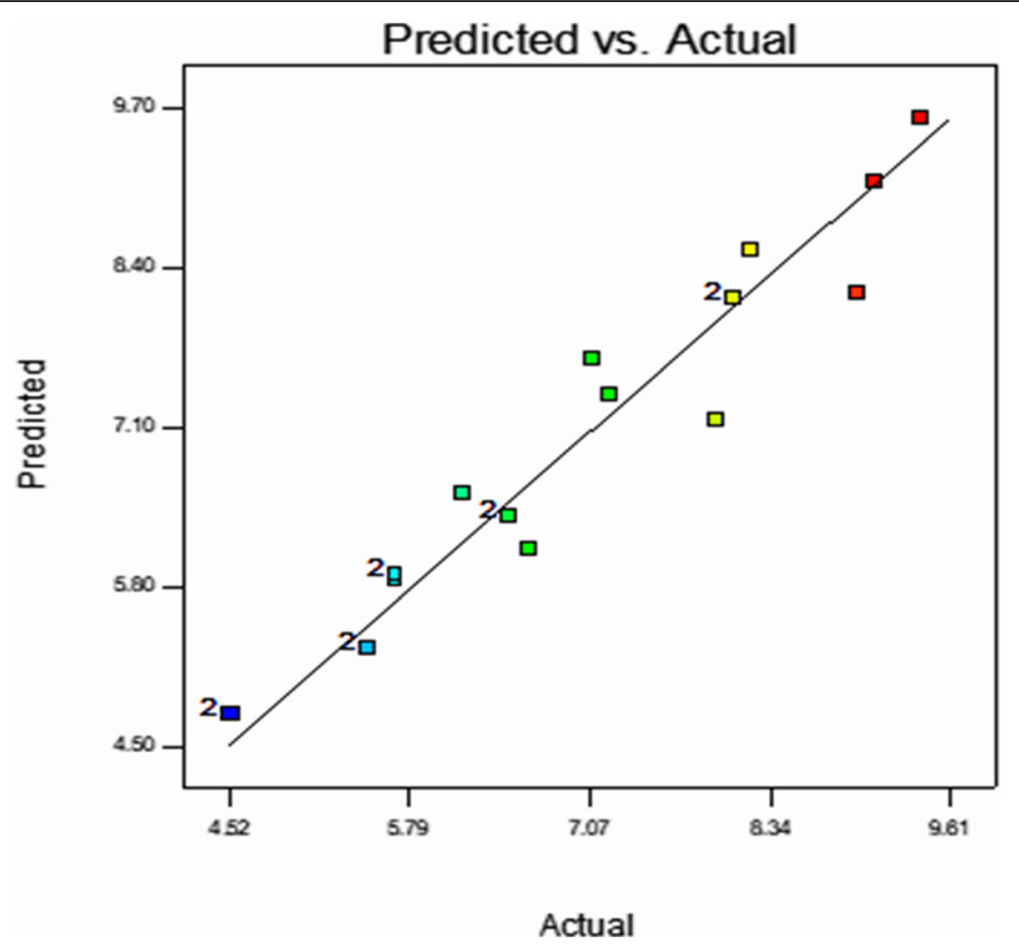

Fig. 6 Removal Predicted (\%) vs. Experimental (\%) of IC dye utilizing activated carbonaceous material (tea waste) obtained from the Response Surface Methodology

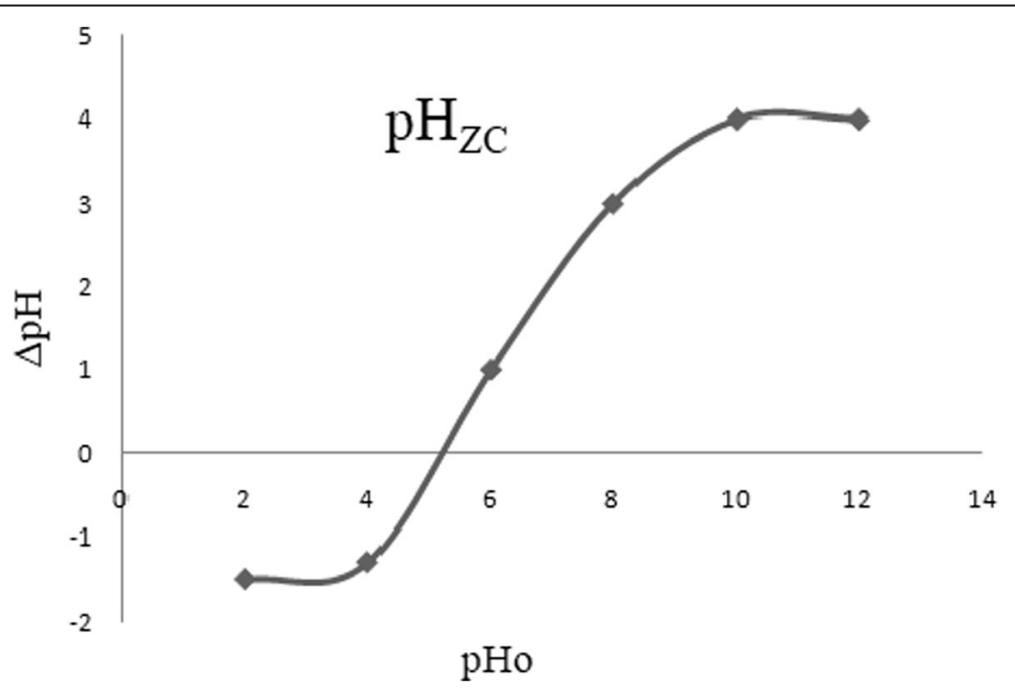

Fig. 7 Plot of the variation of $\Delta \mathrm{pH}=\mathrm{pH}_{\mathrm{f}}-\mathrm{pH}_{\circ}$ vs. $\mathrm{pH}_{\circ}$ 


\section{(a)}

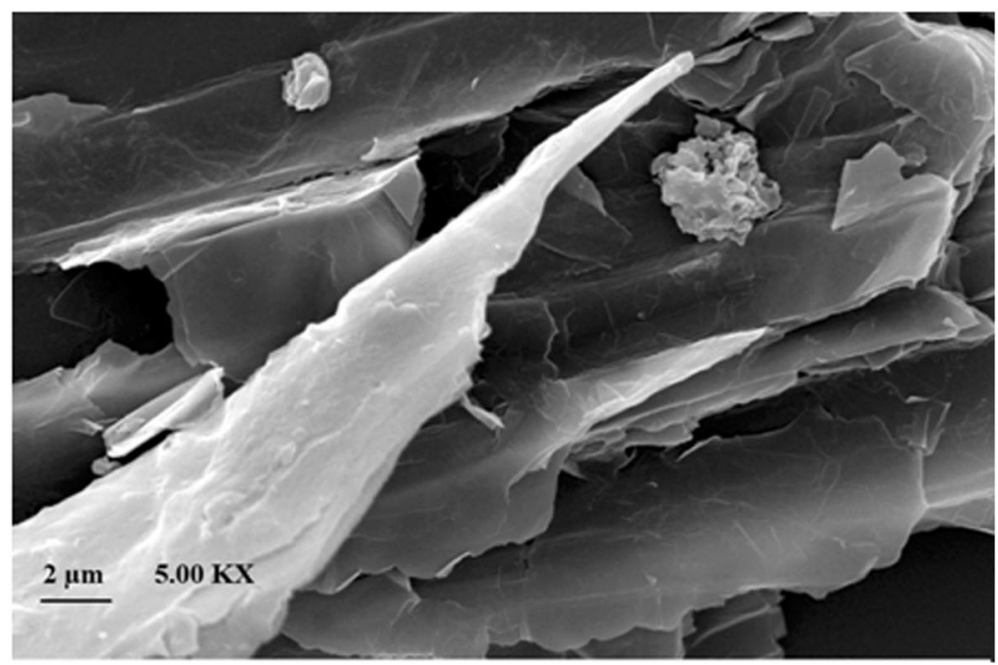

(b)

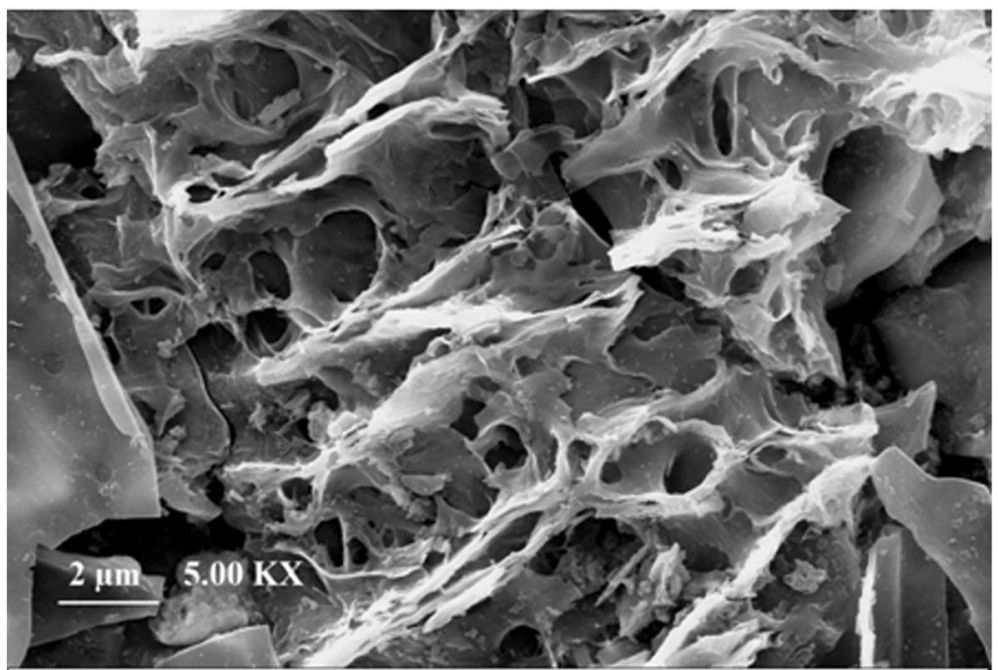

Fig. 8 SEM image of untreated tea waste biochar and treated tea waste biochar (activated carbonaceous material (tea waste))

repetitive use of adsorbent with insignificant loss of functionality.

\section{Comparison of adsorption capacity of IC dye for various adsorbent material}

The comparison of various adsorbent material used for IC dye adsorption and this present study is reported in Table 4 using maximum adsorption capacity as comparative parameter. The adsorption capacity of the adsorbent acquired in this study shows that the activated carbonaceous material with macropores constitute of suitable active binding sites with greater affinity for adsorbate. Table 4 result clearly shows that the activated carbonaceous material used in the study shows a better performance than most of other activated carbonaceous material. Nonetheless, artificial commercial activated carbon shows a higher adsorption capacity but major problem is highly costly.

\section{Conclusions}

The present study shows reuse of domestic or industrial waste, tea waste which has been thermally and chemically activated using modified Hummer's method and the adsorbent shows great potential in adsorbing indigo carmine dye from aqueous solution during batch study experiments. RSM optimization studies are analyzed and show a very low amount of adsorbent for effective adsorption. Maximum IC adsorption (91\%) was obtained by performing the 


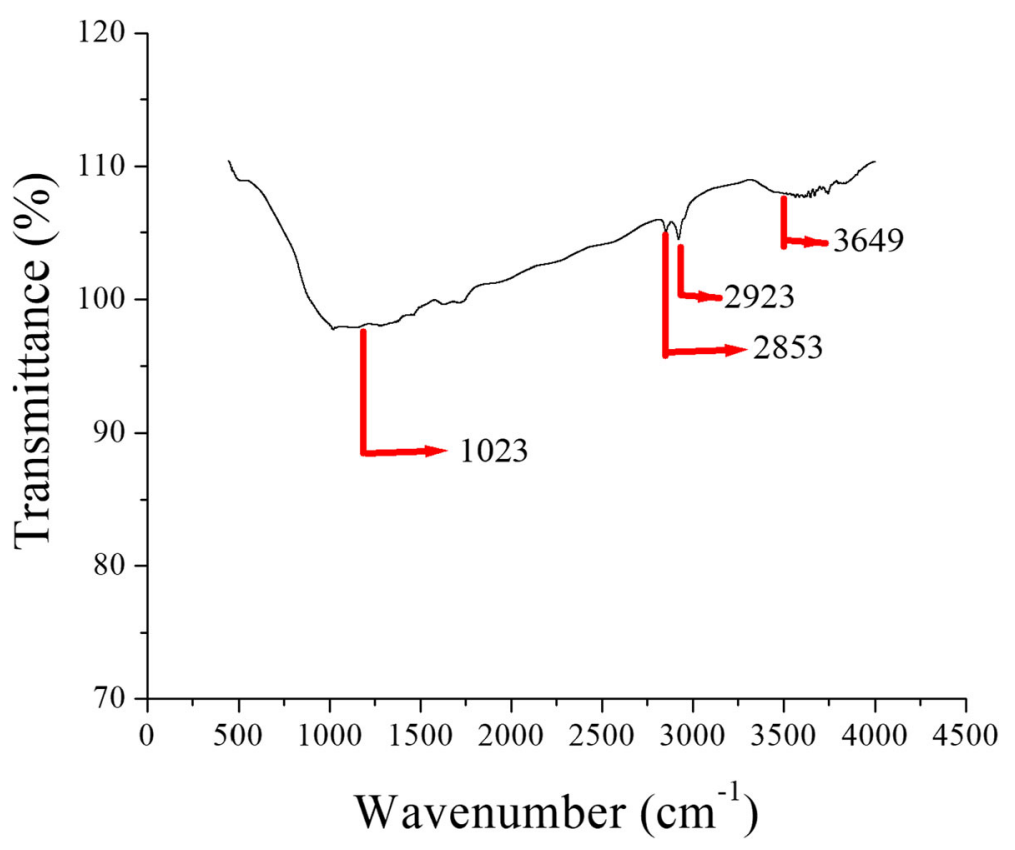

Fig. 9 FT-IR spectroscopy characterization of activated carbonaceous material (tea waste)

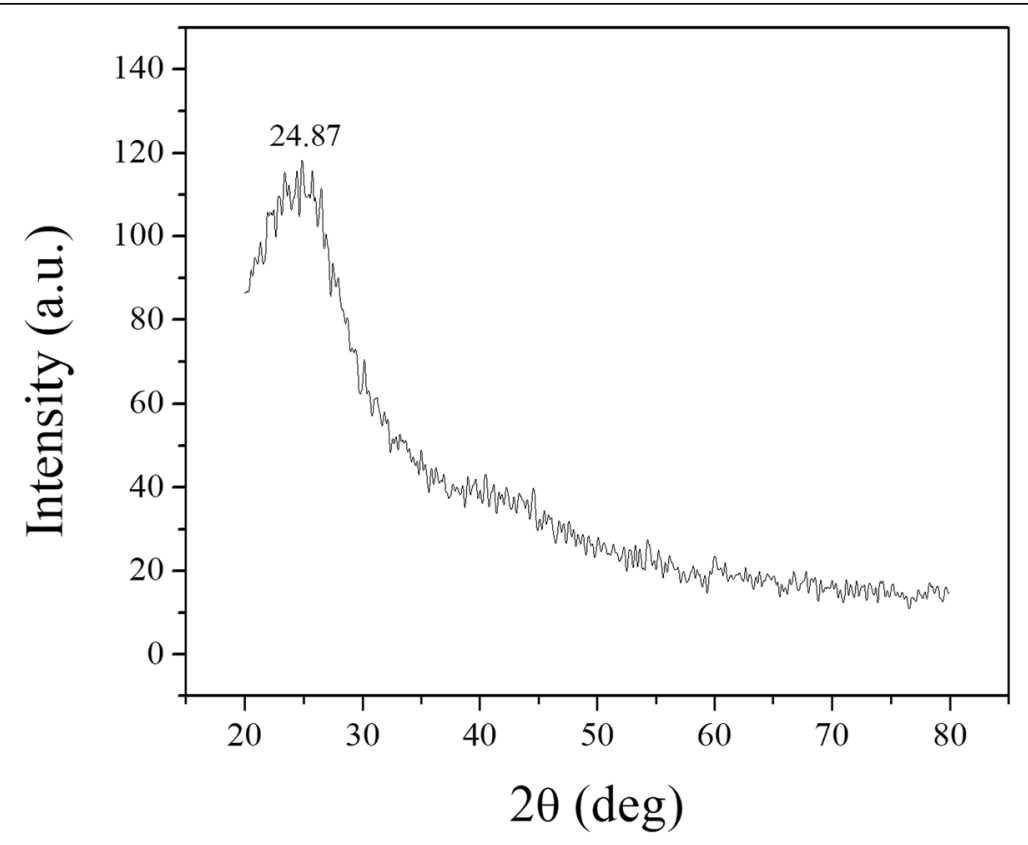

Fig. 10 XRD graph of activated carbonaceous material (tea waste) 


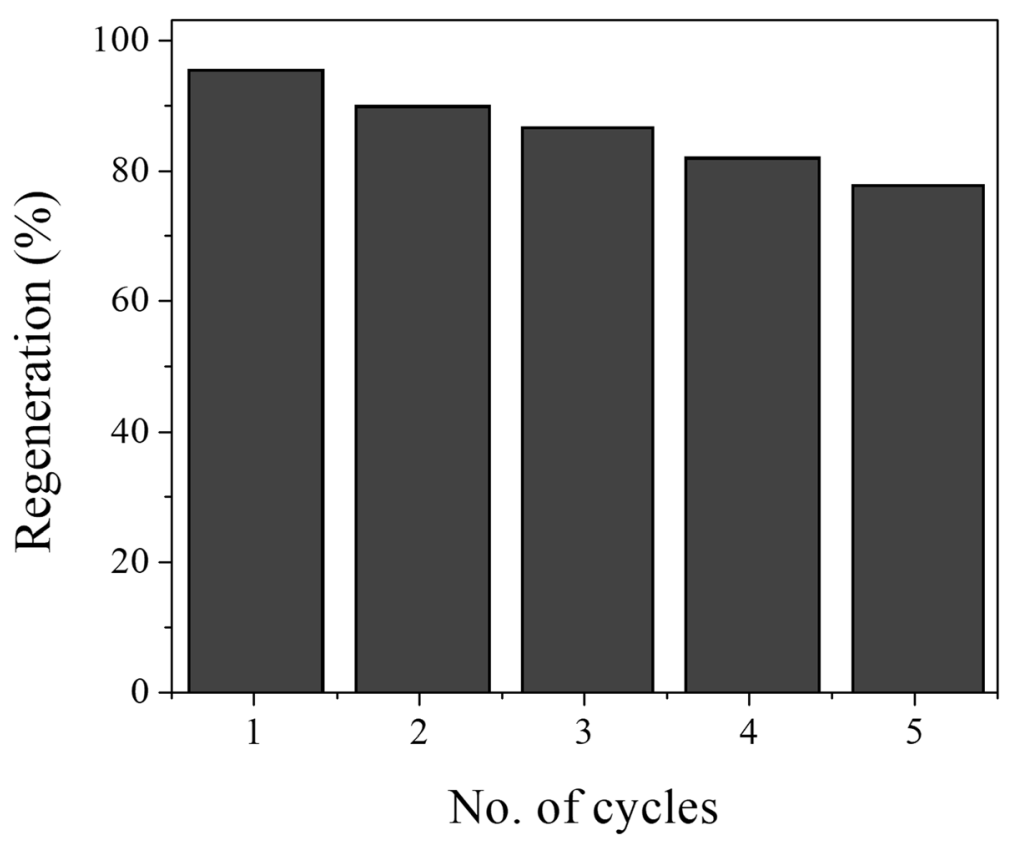

Fig. 11 Regeneration of activated carbonaceous material (tea waste) and its removal efficiency

process under optimum condition. The adsorbent used for the adsorption of IC dye is characterized by various techniques like FT-IR, XRD, SEM and BET which explain the potentiality of successful adsorption of IC dye. Furthermore, Langmuir isotherm adsorption model was found the best with correlation coefficient 0.99 . In this investigation, pseudo second order kinetic model was established. The spontaneity and practicable nature of the IC dye adsorption onto activated carbonaceous material can be predicted by the negative value of $\Delta G^{o}$.

Table 4 Comparison of maximum adsorption capacity for IC dye on some adsorbents

\begin{tabular}{|c|c|c|}
\hline Adsorbent & $\begin{array}{l}\text { Maximum adsorption } \\
\text { capacity }\left(\mathrm{mg} \mathrm{g}^{-1}\right)\end{array}$ & Reference \\
\hline $\begin{array}{l}\text { Carbonaceous material (tea } \\
\text { waste) }\end{array}$ & 20 & This work \\
\hline $\begin{array}{l}\text { Dried cola nut shell activated } \\
\text { with } \mathrm{KOH}\end{array}$ & 13 & [48] \\
\hline Brazil nut shells & 1.1 & [34] \\
\hline $\begin{array}{l}\text { Acacia nilotica (babool) sawdust } \\
\text { activated carbon }\end{array}$ & 4.8 & [49] \\
\hline $\begin{array}{l}\text { Cellulosic waste of citrus } \\
\text { reticulate peels by formaldehyde }\end{array}$ & 15 & [50] \\
\hline $\begin{array}{l}\text { Carbonaceous material from } \\
\text { pyrolysis of sewage sludge }\end{array}$ & 93 & [51] \\
\hline Commercial activated carbon & 79 & {$[52]$} \\
\hline
\end{tabular}

\section{Acknowledgements}

Authors in this paper like to express gratitudeto the Department of Chemical Engineering, Jadavpur University and the Department of Food Technology, Guru Nanak Institute of Technology for allowing the research work to be conducted.

\section{Authors' contributions}

D. Sikdar and S. Goswami carried out the experiments. Manuscript was written D. Sikdar, P. Das supervised the research work. The author(s) read and approved the final manuscript.

\section{Funding}

Not applicable.

Availability of data and materials

All data generated or analyzed during this study are available with the author.

\section{Competing interests}

The authors declare they have no competing interests.

Received: 29 April 2020 Accepted: 30 October 2020

Published online: 23 November 2020

\section{References}

1. Aljeboree AM, Alshirifi AN, Alkaim AF. Kinetics and equilibrium study for the adsorption of textile dyes on coconut shell activated carbon. Arab J Chem. 2017;10:\$3381-93.

2. Dalaran M, Emik S, Guclu G, lyim TB, Ozgumus S. Study on a novel polyampholyte nanocomposite superabsorbent hydrogels: synthesis, characterization and investigation of removal of indigo carmine from aqueous solution. Desalination. 2011;279:170-82.

3. Priya ES, Selvan PS. Water hyacinth (Eichhornia crassipes) - an efficient and economic adsorbent for textile effluent treatment - a review. Arab J Chem. 2017;10:S3548-58.

4. Beltran-Heredia J, Sanchez-Martin J, Delgado-Regalado A. Removal of carmine indigo dye with Moringa oleifera seed extract. Ind Eng Chem Res. 2009;48:6512-20. 
5. Lakshmi UR, Srivastava VC, Mall ID, Lataye DH. Rice husk ash as an effective adsorbent: evaluation of adsorptive characteristics for indigo carmine dye. J Environ Manage. 2009;90:710-20.

6. Holkar CR, Jadhav AJ, Pinjari DV, Mahamuni NM, Pandit AB. A critical review on textile wastewater treatments: possible approaches. J Environ Manage. 2016;182:351-66.

7. Secula MS, Cretescu I, Petrescu S. An experimental study of indigo carmine removal from aqueous solution by electrocoagulation. Desalination. 2011; 277:227-35

8. Ahirwar D, Bano M, Khan F. Synthesis of mesoporous $\mathrm{TiO}_{2}$ and its role as a photocatalyst in degradation of indigo carmine dye. J Sol-Gel Sci Techn. 2016;79:228-37.

9. Li HX, Xu B, Tang L, Zhang JH, Mao ZG. Reductive decolorization of indigo carmine dye with Bacillus sp. MZS10. Int Biodeter Biodegr. 2015; 103:30-7.

10. Hashemian S, Sadeghi B, Mangeli M. Hydrothermal synthesis of nano cavities of Al-MCF for adsorption of indigo carmine from aqueous solution. J Ind Eng Chem. 2015;21:423-7.

11. Ramesh TN, Kirana DV, Ashwini A, Manasa TR. Calcium hydroxide as low cost adsorbent for the effective removal of indigo carmine dye in water. J Saudi Chem Soc. 2017;21:165-71.

12. Hu YC, Chen X, Liu ZQ, Wang GJ, Liao SJ. Activated carbon doped with biogenic manganese oxides for the removal of indigo carmine. J Environ Manage. 2016;166:512-8

13. Sahmoune MN. Performance of Streptomyces rimosus biomass in biosorption of heavy metals from aqueous solutions. Microchem J. 2018;141:87-95.

14. Agorku ES, Kuvarega AT, Mamba BB, Pandey AC, Mishra AK. Enhanced visible-light photocatalytic activity of multi-elements-doped $\mathrm{ZrO}_{2}$ for degradation of indigo carmine. J Rare Earth 2015;33:498-506.

15. de Carvalho TEM, Fungaro DA, Magdalena CP, Cunico P. Adsorption of indigo carmine from aqueous solution using coal fly ash and zeolite from fly ash. J Radioanal Nucl Ch. 2011;289:617-26.

16. Danish M, Khanday WA, Hashim R, Sulaiman NSB, Akhtar MN, Nizami M Application of optimized large surface area date stone (Phoenix dactylifera) activated carbon for rhodamin B removal from aqueous solution: Box-Behnken design approach. Ecotox Environ Safe. 2017;139:280-90.

17. Gupta VK, Mohan D, Sharma S, Sharma M. Removal of basic dyes (rhodamine B and methylene blue) from aqueous solutions using bagasse fly ash. Sep Sci Technol. 2000;35:2097-113.

18. Gupta VK, Suhas, Ali I, Saini VK. Removal of rhodamine B, fast green, and methylene blue from wastewater using red mud, an aluminum industry waste. Ind Eng Chem Res. 2004;43:1740-7.

19. Jain AK, Gupta VK, Bhatnagar A, Jain S, Suhas S. A comparative assessment of adsorbents prepared from industrial wastes for the removal of cationic dye. J Indian Chem Soc. 2003;80:267-70

20. Zhang Z, Luo XS, Liu YN, Zhou PX, Ma GF, Lei ZQ, et al. A low cost and highly efficient adsorbent (activated carbon) prepared from waste potato residue. J Taiwan Inst Chem E. 2015;49:206-11.

21. Nakamura T, Hirata M, Kawasaki N, Tanada S, Tamura T, Nakahori Y. Decolorization of indigo carmine by charcoal from extracted residue of coffee beans. J Environ Sci Heal A. 2003;38:555-62.

22. Satayeva AR, Howell CA, Korobeinyk AV, Jandosov J, Inglezakis VJ, Mansurov ZA, et al. Investigation of rice husk derived activated carbon for removal of nitrate contamination from water. Sci Total Environ. 2018;630:1237-45.

23. Baysal M, Bilge K, Yilmaz B, Papila M, Yurum Y. Preparation of high surface area activated carbon from waste-biomass of sunflower piths: kinetics and equilibrium studies on the dye removal. J Environ Chem Eng. 2018;6:1702-13.

24. Li YC, Shao JG, Wang XH, Deng Y, Yang HP, Chen HP. Characterization of modified biochars derived from bamboo pyrolysis and their utilization for target component (furfural) adsorption. Energ Fuel. 2014; 28:5119-27

25. Goswami S, Banerjee P, Datta S, Mukhopadhayay A, Das P. Graphene oxide nanoplatelets synthesized with carbonized agro-waste biomass as green precursor and its application for the treatment of dye rich wastewater. Process Saf Environ. 2017;106:163-72.
26. Hummers WS, Offeman RE. Preparation of graphitic oxide. J Am Chem Soc. 1958;80:1339.

27. Langmuir I. The adsorption of gases on plane surfaces of glass, mica and platinum. J Am Chem Soc. 1918;40:1361-403.

28. Mittal A, Mittal J, Malviya A, Gupta VK. Adsorptive removal of hazardous anionic dye "Congo red" from wastewater using waste materials and recovery by desorption. J Colloid Interf Sci. 2009;340:16-26.

29. Temkin M, Pyzhev V. Kinetics of ammonia synthesis on promoted iron catalysts. Acta Physicochim URS. 1940;12:327-56

30. Weber TW, Chakravorti RK. Pore and solid diffusion models for fixed-bed adsorbers. AlChE J. 1974;20:228-38.

31. Ho YS, McKay G. Kinetic models for the sorption of dye from aqueous solution by wood. Process Saf Environ. 1998;76:183-91.

32. Weber WJ, Morris JC. Kinetics of adsorption on carbon from solution. J Sanit Eng Div. 1963;89:31-60.

33. Gurses $A$, Yalcin $M$, Dogar $C$. Electrocoagulation of some reactive dyes: a statistical investigation of some electrochemical variables. Waste Manage. 2002:22:491-9.

34. Brito SMD, Andrade HMC, Soares LF, de Azevedo RP. Brazil nut shells as a new biosorbent to remove methylene blue and indigo carmine from aqueous solutions. J Hazard Mater. 2010;174:84-92.

35. Mittal A, Mittal J, Kurup L. Batch and bulk removal of hazardous dye, indigo carmine from wastewater through adsorption. J Hazard Mater. 2006:137:591-602.

36. Banerjee P, Sau S, Das P, Mukhopadhayay A. Optimization and modelling of synthetic azo dye wastewater treatment using graphene oxide nanoplatelets: characterization toxicity evaluation and optimization using artificial neural network. Ecotox Environ Safe. 2015; 119:47-57.

37. Babu AN, Reddy DS, Sharma P, Kumar GS, Ravindhranath K, Mohan GVK. Removal of hazardous indigo carmine dye from waste water using treated red mud. Mater Today-Proc. 2019;17:198-208.

38. Rathour R, Das P, Aikat K. Microwave-assisted synthesis of graphene and its application for adsorptive removal of malachite green: thermodynamics, kinetics and isotherm study. Desalin Water Treat. 2016 57:7312-21

39. Ramesha GK, Kumara AV, Muralidhara HB, Sampath S. Graphene and graphene oxide as effective adsorbents toward anionic and cationic dyes. J Colloid Interf Sci. 2011:361:270-7.

40. Mukherjee M, Goswami S, Banerjee P, Sengupta S, Das P, Banerjee PK, et al. Ultrasonic assisted graphene oxide nanosheet for the removal of phenol containing solution. Environ Technol Inno. 2019;13:398-407.

41. Tseng RL, Tseng SK, Wu FC. Preparation of high surface area carbons from corncob with $\mathrm{KOH}$ etching plus $\mathrm{CO}_{2}$ gasification for the adsorption of dyes and phenols from water. Colloid Surface A. 2006; 279:69-78.

42. Senthilkumaar S, Varadarajan PR, Porkodi K, Subbhuraam C. Adsorption of methylene blue onto jute fiber carbon: kinetics and equilibrium studies. J Colloid Interf Sci. 2005:284:78-82.

43. Mullet M, Fievet P, Szymczyk A, Foissy A, Reggiani JC, Pagetti J. A simple and accurate determination of the point of zero charge of ceramic membranes. Desalination. 1999;121:41-8.

44. Angin D. Production and characterization of activated carbon from sour cherry stones by zinc chloride. Fuel. 2014;115:804-11.

45. Koseoglu E, Akmil-Basar C. Preparation, structural evaluation and adsorptive properties of activated carbon from agricultural waste biomass. Adv Powder Technol. 2015;26:811-8.

46. Banerjee P, Das P, Zaman A, Das P. Application of graphene oxide nanoplatelets for adsorption of Ibuprofen from aqueous solutions: evaluation of process kinetics and thermodynamics. Process Saf Environ. 2016:101:45-53

47. Tushar MSHK, Mahinpey N, Khan A, Ibrahim H, Kumar P, Idem R. Production, characterization and reactivity studies of chars produced by the isothermal pyrolysis of flax straw. Biomass Bioenerg. 2012;37:97-105

48. Odogu AN, Daouda K, Desire BBP, Nsami NJ, Mbadcam KJ. Removal of indigo carmine dye (IC) by batch adsorption method onto dried cola nut shells and its active carbon sciences from aqueous medium. Int J Eng Sci Res Tech. 2016;5:874-87. 
49. Gupta TB, Lataye DH. Adsorption of indigo carmine dye onto Acacia nilotica (babool) sawdust activated carbon. J Hazard Toxic Radioact Waste. 2017;21: 04017013.

50. Rehman R, Zafar J, Nisar H. Adsorption studies of removal of indigo caramine dye from water by formaldehyde and urea treated cellulosic waste of citrus reticulata peels. Asian J Chem. 2014;26:43-7.

51. Gutierrez-Segura E, Solache-Rios M, Colin-Cruz A. Sorption of indigo carmine by a Fe-zeolitic tuff and carbonaceous material from pyrolyzed sewage sludge. J Hazard Mater. 2009;170:1227-35.

52. Harrache Z, Abbas M, Aksil T, Trari M. Thermodynamic and kinetics studies on adsorption of indigo carmine from aqueous solution by activated carbon. Microchem J. 2019;144:180-9.

\section{Publisher's Note}

Springer Nature remains neutral with regard to jurisdictional claims in published maps and institutional affiliations.

Ready to submit your research? Choose BMC and benefit from:

- fast, convenient online submission

- thorough peer review by experienced researchers in your field

- rapid publication on acceptance

- support for research data, including large and complex data types

- gold Open Access which fosters wider collaboration and increased citations

- maximum visibility for your research: over $100 \mathrm{M}$ website views per year

At BMC, research is always in progress.

Learn more biomedcentral.com/submissions 